\title{
Effects of probiotic, prebiotic, and synbiotic with and without feed restriction on performance, hematological indices and carcass characteristics of broiler chickens
}

\author{
Hassan M. Abdel-Hafeez ${ }^{1}$, Elham S. E. Saleh ${ }^{1}$, Samar S. Tawfeek', \\ Ibrahim M. I. Youssef ${ }^{1, *}$, and Asmaa S. A. Abdel-Daim ${ }^{1}$
}

\author{
* Corresponding Author: Ibrahim M. I. Youssef \\ Tel: +20-82-2322066, Fax: +20-82-2327982, \\ E-mail: Ibrahim.Youssef@vet.bsu.edu.eg \\ 'Department of Nutrition and Clinical Nutrition, \\ Faculty of Veterinary Medicine, Beni-Suef University, \\ Beni-Suef 62511, Egypt
}

Submitted Jul 13, 2016; Revised Aug 4, 2016; Accepted Sept 10, 2016
Objective: This study was conducted to investigate the effects of probiotic, prebiotic and synbiotic with and without feed restriction on broilers performance, blood parameters, carcass characteristics, and feed cost of production from 1 to 56 days of age.

Methods: Two hundred and forty unsexed one day-old chicks of Arbor Acres breed were used. Two trials, I and II, were conducted, with 120 birds in both. Each trial was divided into 4 equal groups. The birds in trial I were fed ad libitum throughout the experiment, while the chicks in trial II were fed ad libitum during the first week of age, then subjected to 5 hours/d of feed restriction from the beginning of the second week up to the end of the experiment. In both trials, the birds in group 1 were fed on a control diet while the other groups were given the same control diet supplemented either with a probiotic in group 2, prebiotic in group 3, or synbiotic in group 4.

Results: It was found that chicks fed diets supplemented with probiotic, prebiotic and synbiotic (with and without feed restriction) exhibited higher body weight and feed efficiency than chicks fed the control diets. The feed additives in both trials did not affect hemoglobin, serum total protein, albumin, globulin, glucose, and total cholesterol, except the packed cell volume which was increased in the additive treatments with restriction at the end of the experiment. Moreover, the dietary treatments did not influence the carcass yield. However, the relative weights of liver, gizzard and proventriculus, small intestine and bursa of fabricius were found to be increased. The additives decreased the visible fat in the carcass, with more decreasing effect in the additive groups with restriction. The lowest feed cost per $\mathrm{kg}$ of weight gain was observed in the birds fed diets supplemented with synbiotic, probiotic and prebiotic. Feed restriction improved the feed conversion ratio, economic return, but decreased the feed intake, serum total cholesterol and visible fat in comparison with non-restricted groups. Conclusion: The biological feed additives could be routinely added to broiler diets, especially when a feed restriction program is followed. Finally, it can be recommended to restrict feed, and add probiotic or synbiotic to increase weight, improve feed conversion rate and reduce feed cost of production.

Keywords: Broilers; Probiotic; Prebiotic; Synbiotic; Feed Restriction; Performance

\section{INTRODUCTION}

Probiotics are microbial feed supplements which beneficially affect the host by improving its intestinal microbial balance and the intestinal mucosal barrier against deleterious agents [1]. In the meantime, prebiotics have been defined as non-digestible substances that provide a beneficial physiological effect on the host by selectively stimulating the favourable growth or activity of a limited number of indigenous bacteria [2]. A combination of probiotics and 
prebiotics as a single product is called synbiotics. It is a form of synergism that improves and optimizes the nutrient digestion and absorption [3]. The probiotic with its prebiotic food can survive well in the digestive system and could reduce the count of pathogenic bacteria and increase the population of useful microflora in gut [4].

Some manipulatory procedures to the feeding strategies of poultry such as feed restriction can be applied in order to improve feed conversion and cost, and reducing metabolic diseases and fat deposition in broiler carcasses [5]. Maheri-Sis et al [6] evaluated the effect of several feed restriction programs at different phases of age on performance and carcass yield of broiler chickens. The best age for restriction was found to be between the second and third weeks of age, as before 7 days of age the restriction is liable to cause intestinal underdevelopment and productive performance decrease in broilers. Rosa et al [7] suggested a restriction of feed in broilers for two week-period to obtain complete compensation in growth.

Long period of feed restriction may induce a great stress on birds. Biological feed additives have shown to alleviate the stress caused by feed restriction and improve the immunocompetence of birds [8]. However, Saffar and Khajali [9] found that probiotics did not ameliorate the negative effects of feed restriction on broiler performance. As far as the literature denotes, the effect of biological feed additives on feed restriction stresses still has not been well studied. Therefore, the aim of the present study was to investigate the effect of the feed additives, probiotic, prebiotic and synbiotic, with and without feed restriction on production performance, blood parameters, carcass characteristics, and feed cost of production in broilers. This was done to evaluate the effects of feed additives and feed restriction independently. Moreover, the impact of used additives in alleviating the side effects, if any, of restriction was investigated.

\section{MATERIALS AND METHODS}

\section{Birds and management}

A total number of 240 one-day old broiler (Arbor Acres) chicks were procured from a commercial hatchery with an average weight of $46 \mathrm{~g}$. The chicks were weighed individually, marked by using plastic rings with different colours, and distributed at random, into eight groups with 30 birds each. The birds, of each experimental group, were housed in a floor pen and wheat straw was used as a litter. A lightening period of $23 \mathrm{~h}$. per day was provided throughout the experimental period. The initial brooding temperature was $33^{\circ} \mathrm{C}$ in the first week of age and reduced gradually $2^{\circ} \mathrm{C}$ per week until reaching about $20^{\circ} \mathrm{C}$ at the end of the experiment. Chicks were allowed to have free access to water and feed along the experimental period except in the groups used to test feed restriction.

\section{Experimental design and diets}

Two trials, I and II, were conducted at the same time and location, with 120 chicks in both. Each trial was divided into 4 equal groups. Trial I included four groups fed on ad libitum basis during the experimental period, while the feed restriction in trial II was applied on the other four groups. In trial II, the chicks in the different groups were fed ad libitum during the first week of age, while from the beginning of the second week up to the end of the experimental period, the birds were subjected to 5 hours of feed restriction daily (from 9 to 12 am and from 1 to $3 \mathrm{pm}$ ).

The experimental diets used in this study were formulated from the commonly used feedstuffs. The used ingredients were analyzed for proximate composition using the standard methods according to AOAC [10]. Based on the nutrient contents of the ingredients, the diets were formulated to satisfy the broiler's nutritional needs stated by NRC for poultry [11] which recommends a metabolizable energy density of $3,200 \mathrm{kcal} / \mathrm{kg}$ in all the phase-diets and $23 \%, 20 \%$, and $18 \%$ crude protein in starter, grower and finisher, respectively. The diets of the different chick groups were formulated to be isocaloric and isonitrogenous. The physical and chemical composition of the different diets is displayed in Table 1 .

The experimental period lasted for 8 weeks and included 3 feeding phases starter ( 0 to $3 \mathrm{wk}$ ), grower ( 3 to $6 \mathrm{wk}$ ) and finisher ( 6 to $8 \mathrm{wk}$ ) diets. It included four formulated diets in each feeding phase and in each trial. The birds in group 1 were fed on the negative control diet (without feed additives). The other groups were given the same control diet supplemented either with a probiotic (Enhancer, at a dosage of $0.250 \mathrm{~kg} / \mathrm{ton}$ in the three feeding phases) in group 2, or prebiotic (Bio-Mos, at a rate of $2.0,1.0$, and $0.5 \mathrm{~kg} / \mathrm{ton}$ in starter, grower, and finisher phase, respectively) in group 3 , or synbiotic in group 4 . The synbiotic used in this experiment was designed to be half the amounts of the used probiotic and prebiotic. Accordingly, the synbiotic was a mixture of $0.125 \mathrm{~kg}$ probiotic (Enhancer, USA) with 1.0, 0.5 , and $0.25 \mathrm{~kg}$ of prebiotic (Bio-Mos, USA) in the three phase diets, reaching a level of $1.13,0.63,0.38 \mathrm{~kg} /$ ton in starter, grower and finisher diets, respectively. The additives added substituted equal amounts of yellow corn and their levels were provided according to the recommendations of the producing companies. Probiotic "Enhancer" is a product of Performance Plus International Company (Naperville, Chicago, IL, USA). Each gram of the product contains totally not less than $5 \times 10^{10}$ colony forming units of both Bacillus licheniformis and Bacillus subtilis. The prebiotic "Bio-Mos" is a product of Alltech Company, Nicholasville, KY, USA. It is a commercial product of phosphorylated mannan-oligosaccharides (MOS) derived from the cell wall of certain strains of Saccharomyces cerevisiae. The same diets were used in trial II but with a feed restriction regime application.

\section{Data collection}

Growth performance: The chicks were individually weighed to 
Table 1. Physical and chemical composition (\%) of the control diets

\begin{tabular}{lccc}
\hline \multirow{2}{*}{ Ingredient } & \multicolumn{3}{c}{ Diets } \\
\cline { 2 - 4 } & Starter & Grower & Finisher \\
\hline Physical composition & & & \\
Yellow corn, ground & 45.77 & 52.53 & 60.72 \\
Soybean meal & 34.94 & 35.20 & 29.10 \\
Corn gluten meal & 6.00 & 0.00 & 0.00 \\
Vegetable oil) & 7.23 & 6.99 & 5.32 \\
Molasses, cane & 2.00 & 2.00 & 2.00 \\
Limestone, ground & 1.40 & 1.35 & 1.29 \\
Dicalcium phosphate & 1.75 & 1.20 & 0.96 \\
Common salt & 0.48 & 0.35 & 0.27 \\
DL-Methionine & 0.13 & 0.08 & 0.04 \\
Minerals and vitamins premix ${ }^{3)}$ & 0.30 & 0.30 & 0.30 \\
Chemical composition & & & \\
Metabolizable energy (kcal/kg) & 3,204 & 3,203 & 3,201 \\
Dry matter & 91.45 & 91.18 & 90.83 \\
Crude protein & 23.03 & 20.06 & 18.01 \\
Methionine & 0.51 & 0.39 & 0.32 \\
Methionine+Cystine & 0.90 & 0.72 & 0.62 \\
Lysine & 1.12 & 1.08 & 0.93 \\
Ether extract & 9.52 & 9.38 & 7.87 \\
Crude fiber & 3.05 & 3.13 & 2.92 \\
Calcium & 1.04 & 0.90 & 0.81 \\
Phosphorus, available & 0.46 & 0.35 & 0.30 \\
Sodium & 0.20 & 0.15 & 0.12 \\
\hline & &
\end{tabular}

${ }^{1)}$ Vegetable oil composed of $75 \%$ sunflower oil and $25 \%$ soybean oil.

${ }^{2)}$ DL-Methionine is patent commercial product of Decosta company, USA, containing $99 \%$ methionine.

${ }^{3)}$ Poultry mineral and vitamin premix (Avimix, Agri - Vet Company, Egypt): each $3 \mathrm{~kg}$ contains vitamin $A, 12,000,000 \mathrm{IU}$; vitamin $\mathrm{D}_{3}, 2,000,000 \mathrm{IU}$; vitamin $\mathrm{E}, 10,000 \mathrm{mg}$; vitamin $K_{3}, 2,000$ mg; vitamin $B_{1}, 1,000$ mg, vitamin $B_{2}, 5,000$ mg; vitamin $B_{6}, 1,500$ mg; vitamin $B_{12}, 10$ mg; biotin, 50 mg; pantothenic acid, 10,000 mg; nicotinic acid, 30,000 mg; folic acid, 1,000 mg, choline chloride, 250,000 mg; Mn, 60,000 mg; Zn, 50,000 mg; Fe, 30,000 mg; Cu, 10,000 mg; I, 1,000 mg; Se, $100 \mathrm{mg}$; Co, $100 \mathrm{mg}$; and calcium carbonate up to $3 \mathrm{~kg}$.

the nearest gram at the beginning of the experiment, and every week thereafter till the end of the experiment. The gain in body weight (BW) of birds per week was calculated as the difference between the initial and end weight at a given week. The diets were offered to the chicks daily at 9 o'clock in the morning and the weekly feed intake was calculated by the difference between the offered and remained amounts. The total feed consumption per week was divided by the number of birds in each group to obtain the average weekly feed intake per bird. The feed intake was calculated after correction for that used by dead birds. The feed conversion ratio was calculated by dividing the amount of feed consumed in a certain period by the gain in weight at the same period (with consideration of dead birds), expressed in the same weight units. During the experimental period, daily mortalities were recorded for each group and mortality rate was calculated.

Blood parameters: Blood samples were collected from the brachial vein of 5 chicks in each group at 21, 42, and 56 days of age. The samples were collected into eppendorf tubes with ethylenediaminetetraacetic acid (EDTA), as an anticoagulant to measure hemoglobin and packed cell volume. Other blood samples were collected in non-EDTA tubes and allowed to clot for one hour, at room temperature, and then centrifuged at $3,000 \mathrm{rpm}$ for $20 \mathrm{~min}$, for serum separation. Collected sera were stored in a deep freezer at $-20^{\circ} \mathrm{C}$ until chemically analyzed. At the time of analysis, the samples were thawed and analyzed for total protein, albumin, glucose and total cholesterol.

Hemoglobin concentration $(\mathrm{g} / \mathrm{dL})$ was estimated using hemoglobin kit according to cyanomethemoglobin method and the packed cell volume (\%) by microhematocrite centrifuge. Serum total protein $(\mathrm{g} / \mathrm{dL})$ was determined colorimetrically, while albumin $(\mathrm{g} / \mathrm{dL})$ value was measured by bromocresol green method. Globulin concentration $(\mathrm{g} / \mathrm{dL})$ was calculated as the difference between total protein and albumin. Serum glucose $(\mathrm{mg} / \mathrm{dL})$ and total cholesterol $(\mathrm{mg} / \mathrm{dL})$ were also monitored colorimetrically. Commercial test kits of Diamond diagnostic company, Egypt were used for measuring the previous mentioned blood parameters except the total protein which was determined by using a reagent kit of Biostc Company, Egypt.

Carcass characteristics: Five birds from each group, close to the average live BW, were selected at the end of the grower and finisher phases of the experiment. Birds were weighed to the nearest gram, subjected to $24 \mathrm{~h}$-feed withdrawal with free access to water, reweighed and slaughtered by neck cutting. After five minutes of bleeding, each bird was scalded, defeathered, and eviscerated after removal of head, neck and legs. The carcass without giblets was weighed, expressed as a percentage of its live weight and considered as the carcass yield. In addition, the weight of the liver (without gall bladder), gizzard and proventriculus, heart, spleen, bursa of fabricius, small intestine, the two caeca, and visible fat (around the viscera, gizzard, and subcutaneously) was recorded and its relation to the live BW of the bird, in percentage, was calculated.

Feed cost of production: To determine the economic efficiency for meat production, the cost of each one kg BW gain was calculated, in each feeding phase and at the overall of the experimental period. In each feeding phase, the cost of the diets consumed was divided by the weight gain, or the price of each $\mathrm{kg}$ feed was multiplied by the rate of feed conversion, to get the cost of each $\mathrm{kg}$ gain. Overall the experiment, the cost of the diets consumed in each treatment was calculated and divided by the total weight gain of the chicks to get the cost of each $\mathrm{kg}$ gain produced. The cost of the experimental diets was estimated depending upon the local current prices of the different ingredients and additives at the time of the experiment.

\section{Statistical analysis}

The statistical analyses were performed using SPSS statistical program (IBM, version 20, Chicago, IL, USA, 2011). The data were analyzed using the general linear model (GLM) procedure. Analysis of variance (ANOVA) tests were used for analyses of 
Table 2. Body weight development (in gram) of the chicks in the different experimental groups (Mean \pm SEM)

\begin{tabular}{|c|c|c|c|c|c|c|c|c|}
\hline \multirow{3}{*}{$\begin{array}{l}\text { Age in } \\
\text { weeks }\end{array}$} & \multicolumn{4}{|c|}{ Trial I (Ad libitum feeding) } & \multicolumn{4}{|c|}{ Trial II (Restricted feeding) } \\
\hline & Control & Probiotic & Prebiotic & Synbiotic & Control & Probiotic & Prebiotic & Synbiotic \\
\hline & 1 & 2 & 3 & 4 & 1 & 2 & 3 & 4 \\
\hline 0 & $46.27 \pm 0.58^{\mathrm{Aa}}$ & $46.40 \pm 0.58^{\text {Aa }}$ & $47.08 \pm 0.59^{\mathrm{Aa}}$ & $46.68 \pm 0.58^{\text {Aa }}$ & $46.55 \pm 0.66^{\mathrm{Aa}}$ & $45.69 \pm 0.82^{\mathrm{Aa}}$ & $45.32 \pm 0.680^{\mathrm{Aa}}$ & $46.39 \pm 0.68^{\text {Aa }}$ \\
\hline 1 & $122.23 \pm 4.60^{\mathrm{Aa}}$ & $120.00 \pm 3.85^{\mathrm{Aa}}$ & $125.28 \pm 3.37^{\mathrm{Aa}}$ & $125.39 \pm 4.14^{\mathrm{Aa}}$ & $125.18 \pm 3.49^{\mathrm{Aa}}$ & $125.73 \pm 2.99^{\mathrm{Aa}}$ & $124.64 \pm 3.15^{\mathrm{Aa}}$ & $126.71 \pm 3.28^{\mathrm{Aa}}$ \\
\hline 2 & $345.08 \pm 8.89^{\mathrm{Aa}}$ & $342.52 \pm 8.69^{\mathrm{Aa}}$ & $340.16 \pm 8.41^{\mathrm{Aa}}$ & $372.93 \pm 11.84^{\mathrm{Ab}}$ & $340.48 \pm 11.11^{\mathrm{Aa}}$ & $358.00 \pm 6.07^{\mathrm{Aa}}$ & $343.00 \pm 8.78^{\mathrm{Aa}}$ & $345.04 \pm 6.37^{\mathrm{Aa}}$ \\
\hline 3 & $757.69 \pm 10.23^{\mathrm{Ba}}$ & $746.28 \pm 10.89^{\text {Ba }}$ & $746.64 \pm 7.84^{B}$ & $804.93 \pm 14.99^{\mathrm{cb}}$ & $661.63 \pm 14.73^{\mathrm{Aa}}$ & $704.85 \pm 10.69^{\text {Ba }}$ & $684.50 \pm 14.45^{\mathrm{ABa}}$ & $691.64 \pm 10.20^{A B a}$ \\
\hline 4 & $979.43 \pm 18.09^{\mathrm{Ca}}$ & $999.86 \pm 19.22^{\mathrm{Ca}}$ & $977.32 \pm 13.60^{\mathrm{Ca}}$ & $1103.80 \pm 19.78^{\mathrm{Db}}$ & $834.42 \pm 14.42^{\mathrm{Aa}}$ & $905.69 \pm 12.13^{B C}$ & $885.08 \pm 10.68^{\mathrm{ABab}}$ & $867.60 \pm 15.02^{\text {ABab }}$ \\
\hline 5 & $1,275.65 \pm 16.74^{\mathrm{Da}}$ & $1,406.64 \pm 16.20^{\mathrm{Eb}}$ & $1,312.01 \pm 13.12^{\mathrm{Da}}$ & $1525.16 \pm 19.86^{\mathrm{Fc}}$ & $1,034.62 \pm 14.49^{\mathrm{Aa}}$ & $1,184.00 \pm 16.79^{c c}$ & $1,117.32 \pm 15.14^{\mathrm{Bb}}$ & $1,137.64 \pm 16.97^{B D}$ \\
\hline 6 & $1,590.22 \pm 15.97^{\mathrm{Ca}}$ & $1,898 \cdot 18 \pm 12 \cdot 37^{\mathrm{EC}}$ & $1,689.73 \pm 13.76^{D b}$ & $2,014.60 \pm 18.23^{\mathrm{Fd}}$ & $1,287.37 \pm 25.26^{\text {Aa }}$ & $1,619.57 \pm 18.62^{c d}$ & $1,468.24 \pm 19.41^{\mathrm{Bb}}$ & $1,559.40 \pm 19.61^{\mathrm{BC}}$ \\
\hline 7 & $1,885.69 \pm 23.19^{\mathrm{Ba}}$ & $2,354.40 \pm 19.16^{D C}$ & $2,021.27 \pm 30.43^{\mathrm{cb}}$ & $2,484.89 \pm 19.90^{\mathrm{Ed}}$ & $1,533.00 \pm 34.06^{\mathrm{Aa}}$ & $2,024.51 \pm 30.11^{c c}$ & $1,796.88 \pm 22.69^{\mathrm{Bab}}$ & $1,942.53 \pm 31.39^{B c}$ \\
\hline 8 & $2,171.31 \pm 32.51^{\mathrm{Ba}}$ & $2,774.47 \pm 27.83^{D C}$ & $2,344.00 \pm 33.96^{\mathrm{cb}}$ & $2,907.22 \pm 26.11^{\mathrm{Ed}}$ & $1,748.06 \pm 23.39^{\mathrm{Aa}}$ & $2,414.84 \pm 27.89^{c c}$ & $2,107.88 \pm 30.11^{\mathrm{Bb}}$ & $2,324.94 \pm 34.62^{c c}$ \\
\hline
\end{tabular}

SEM, standard error of the mean.

${ }^{a-d}$ Means within the same row (in each trial independently) with different superscripts are significantly different $(p<0.05)$.

${ }^{A-F}$ Means within the same row (in both trials together) with different superscripts are significantly different $(p<0.05)$.

variance accompanied by Duncan's multiple range test to detect the differences between the treatments. Moreover, ANOVA with repeated measurements was applied for BW results. In addition, the statistical tests were conducted for each trial independently as well as for both trials together. The results are presented as means \pm standard error of the mean. Probability values less than $0.05(\mathrm{p}<0.05)$ was considered significant.

\section{RESULTS}

\section{Performance and feed cost of production}

Data on weekly live BW development, performance and feed cost of production are presented in Table 2 and 3 respectively. The initial BW of chicks did not differ $(\mathrm{p}>0.05)$ between the dietary treatments.

Table 3. Performance data as well as feed cost of production in broiler chicks of the different experimental groups

\begin{tabular}{|c|c|c|c|c|c|c|c|c|}
\hline \multirow{3}{*}{ Parameters } & \multicolumn{4}{|c|}{ Trial I (Ad libitum feeding) } & \multicolumn{4}{|c|}{ Trial II (Restricted feeding) } \\
\hline & Control & Probiotic & Prebiotic & Synbiotic & Control & Probiotic & Prebiotic & Synbiotic \\
\hline & 1 & 2 & 3 & 4 & 1 & 2 & 3 & 4 \\
\hline \multicolumn{9}{|l|}{ Starter phase (0-3 wk) } \\
\hline Weight gain (g) & $711.42 \pm 11.28^{\mathrm{Ca}}$ & $699.88 \pm 10.77^{\mathrm{Ca}}$ & $699.56 \pm 7.92^{\mathrm{Ca}}$ & $758.25 \pm 14.87^{\mathrm{Db}}$ & $615.08 \pm 14.99^{\mathrm{Aa}}$ & $659.16 \pm 10.76^{\mathrm{Ba}}$ & $639.18 \pm 12.31^{\mathrm{ABa}}$ & $645.25 \pm 10.22^{\mathrm{ABa}}$ \\
\hline Feed intake $(\mathrm{g})$ & 997.84 & 820.69 & 910.29 & 872.43 & 776.88 & 742.33 & 757.41 & 715.16 \\
\hline Feed conversion ratio $(\mathrm{g} / \mathrm{g})$ & 1.40 & 1.17 & 1.30 & 1.15 & 1.26 & 1.13 & 1.18 & 1.11 \\
\hline Mortality rate (\%) & - & - & - & - & - & - & - & - \\
\hline Feed cost (LE/kg) & 3.92 & 3.95 & 4.08 & 4.02 & 3.92 & 3.95 & 4.08 & 4.02 \\
\hline Feed cost of production (LE/kg) & 5.49 & 4.62 & 5.30 & 4.62 & 4.94 & 4.46 & 4.81 & 4.46 \\
\hline \multicolumn{9}{|l|}{ Grower phase (3-6 wk) } \\
\hline Weight gain (g) & $832.53 \pm 17.69 \mathrm{~B}^{\mathrm{Ca}}$ & $1,151.90 \pm 14.01^{\mathrm{EC}}$ & $943.09 \pm 15.70^{\mathrm{Db}}$ & $1,209.67 \pm 26.43^{\mathrm{Ed}}$ & $625.74 \pm 27.12^{\text {Aa }}$ & $914.72 \pm 25.04^{B C}$ & $783.74 \pm 22.01^{\mathrm{Bb}}$ & $867.76 \pm 24.39^{\mathrm{cc}}$ \\
\hline Feed intake $(\mathrm{g})$ & $1,521.46$ & $1,936.08$ & $1,665.89$ & $1,951.65$ & $1,103.98$ & $1,478.15$ & $1,311.60$ & $1,374.52$ \\
\hline Feed conversion ratio $(\mathrm{g} / \mathrm{g})$ & 1.83 & 1.68 & 1.77 & 1.61 & 1.76 & 1.62 & 1.67 & 1.58 \\
\hline Mortality rate (\%) & 3.33 & 3.33 & 6.67 & 6.67 & - & 3.33 & 6.67 & - \\
\hline Feed cost (LE/kg) & 3.57 & 3.59 & 3.64 & 3.62 & 3.57 & 3.59 & 3.64 & 3.62 \\
\hline Feed cost of production (LE/kg) & 6.53 & 6.03 & 6.44 & 5.83 & 6.28 & 5.82 & 6.08 & 5.72 \\
\hline \multicolumn{9}{|l|}{ Finisher phase (6-8 wk) } \\
\hline Weight gain (g) & $581.09 \pm 37.05^{\mathrm{Ba}}$ & $876.29 \pm 37.80^{\mathrm{EC}}$ & $654.27 \pm 41.52^{\mathrm{cb}}$ & $892.62 \pm 29.28^{\mathrm{Fc}}$ & $460.69 \pm 28.97^{\mathrm{Aa}}$ & $795.27 \pm 33.36^{D C}$ & $639.64 \pm 23.39^{c b}$ & $765.54 \pm 32.90^{\mathrm{CDC}}$ \\
\hline Feed intake (g) & $1,604.05$ & $1,874.68$ & $1,601.00$ & $1,872.40$ & $1,028.86$ & $1,568.83$ & $1,308.62$ & $1,462.12$ \\
\hline Feed conversion ratio (g/g) & 2.76 & 2.14 & 2.45 & 2.10 & 2.23 & 1.97 & 2.05 & 1.91 \\
\hline Mortality rate (\%) & - & 3.45 & - & - & - & - & - & - \\
\hline Feed cost (LE/kg) & 3.26 & 3.29 & 3.30 & 3.30 & 3.26 & 3.29 & 3.30 & 3.30 \\
\hline Feed cost of production (LE/kg) & 9.00 & 7.04 & 8.09 & 6.93 & 7.27 & 6.48 & 6.77 & 6.30 \\
\hline \multicolumn{9}{|l|}{ The overall period $(0-8 w k)$} \\
\hline Weight gain (g) & $2,125.04 \pm 34.65^{\mathrm{BCa}}$ & $2,728.07 \pm 27.94^{\mathrm{Fc}}$ & $2,296.92 \pm 26.68^{\mathrm{cb}}$ & $2,860.54 \pm 26.21^{\mathrm{Gd}}$ & $1,701.51 \pm 23.67^{\mathrm{Aa}}$ & $2,369.15 \pm 28.12^{\mathrm{Ed}}$ & $2,062.56 \pm 30.22^{\mathrm{Bb}}$ & $2,278.55 \pm 34.68^{\mathrm{DC}}$ \\
\hline Feed intake (g) & $4,123.35$ & $4,631.45$ & 4,177.18 & $4,696.48$ & $2,909.72$ & $3,789.31$ & $3,377.63$ & $3,551.80$ \\
\hline Feed conversion ratio $(\mathrm{g} / \mathrm{g})$ & 1.94 & 1.70 & 1.82 & 1.64 & 1.71 & 1.60 & 1.64 & 1.56 \\
\hline Mortality rate (\%) & 3.33 & 6.67 & 6.67 & 6.67 & - & 3.33 & 6.67 & - \\
\hline Total feed cost (LE/total gain) $)^{11)}$ & 14.58 & 16.35 & 15.07 & 16.72 & 10.32 & 13.41 & 12.17 & 12.66 \\
\hline Feed cost of production (LE/kg) & 6.86 & 5.99 & 6.56 & 5.85 & 6.07 & 5.66 & 5.90 & 5.56 \\
\hline
\end{tabular}

LE, Egyptian pound or Livre Egyptienne.

${ }_{\text {a-d }}$ Means within the same row (in each trial independently) with different superscripts are significantly different $(p<0.05)$.

${ }^{\text {A-F }}$ Means within the same row (in both trials together) with different superscripts are significantly different $(p<0.05)$.

${ }^{1)}$ Total feed cost (LE/total gain) $=$ starter (gain $\times$ feed cost of production) + grower (gain $\times$ feed cost of production)+finisher (gain $\times$ feed cost of production). 
Trial I (Ad libitum feeding): Birds fed diets supplemented with probiotic, prebiotic and synbiotic had a greater $(\mathrm{p}<0.05)$ BW compared with controls. Moreover, synbiotic and probiotic supplemented birds had a greater $(\mathrm{p}<0.01) \mathrm{BW}$ than birds supplemented with the prebiotic. The effect of the added additives on BW started at the fifth week with the probiotic, with an increase of $10 \%$ compared with the control. While, the effect of the prebiotic started at the sixth week with an increase of $6 \%$, and at the second week in the synbiotic group with an increase of $8 \%$. The number of dead birds during the experiment ( 0 to 8 weeks) was one bird (3.33\%) in the control group and two birds (6.67\%) in each of probiotic, prebiotic and synbiotic groups.

The cumulative feed intake during the starter period was not affected among the different experimental groups. However, it increased during grower and finisher periods for birds supplemented with probiotic and synbiotic compared with the prebiotic and control groups. The feed consumption in the prebiotic group was higher than the control one during the grower period but not in the finisher.

The feed conversion ratio (FCR) for birds supplemented with probiotic was 1.17, 1.68, and 2.14 at the starter, grower and finisher periods, respectively, compared with $1.40,1.83$, and 2.76 for the control. In the prebiotic and synbiotic treatments, the feed conversion rate was 1.30 and 1.15 at the starter, 1.77 and 1.61 at the grower, and 2.45 and 2.10 at the finisher, respectively. The cumulative FCR in the 8 weeks was 1.70, 1.82, and 1.64 for probiotic, prebiotic, and synbiotic, respectively, compared with 1.94 for the control, with the clearest effect in synbiotic and probiotic groups.

The cost of feed for the control diet was 3.92, 3.57, and 3.26 LE (Egyptian pound or Livre Egyptienne)/kg at the starter, grower and finisher periods, respectively. While, the cost of $\mathrm{kg}$ feed in diets containing the additives was slightly higher than the control. The additives greatly improved the feed cost of production at the starter, especially in probiotic and synbiotic groups where each $\mathrm{kg}$ gain cost $4.62 \mathrm{LE}$ in both treatments compared with 5.49 LE in the control. At the grower period, the $\mathrm{kg}$ gain produced by the same additives cost 6.03 and 5.83 LE compared with 6.53 LE for the control. At the finisher, each $\mathrm{kg}$ gain in the probiotic, prebiotic, and symbiotic cost 7.04, 8.09, and 6.93 LE, respectively, compared with 9.0 LE in the control. In the total period, the three additives had the least costs but the probiotic and synbiotic had the lowest costs 5.99 and 5.85 LE, respectively, compared with $6.86 \mathrm{LE}$ for the control and 6.56 LE for the prebiotic.

Trial II (Restricted feeding): It was found that the BW of control group reached about 1,748 $\mathrm{g}$ at the 8 th week of which $38 \%$ in the starter, $36 \%$ in the grower, and $26 \%$ in the finisher period, with no clear effect of the restriction on the rate of growth. The other three groups reached at the eighth week about 2,415, 2,108, and $2,325 \mathrm{~g}$ with a percentage of $138 \%, 121 \%$, and $133 \%$ of the control group (100\%). The effect of the added additives on
BW started at the fourth week with an increase of $9 \%$ in the probiotic group, and at the fifth week with an increase of $8 \%$ in the prebiotic and $10 \%$ increase in the synbiotic. It was noticed that at the third week the weight of control group was $13 \%$ less than the ad libitum control and continued in this trend till it was $81 \%$ of the ad libitum weight, so that the BW was $19 \%$ lower at the end of the experiment. Also, the BW of additive groups in this trial was significantly lower $(p<0.05)$ than the corresponding ones in the ad libitum trial, starting also from the third week. The mortality rate throughout the experiment was 3.33\% (one bird) in probiotic group and 6.67\% (two birds) in prebiotic one and no mortality in the control and synbiotic ones.

The cumulative feed intake was not affected among the different experimental groups at the starter period. However, it was increased during grower and finisher periods for birds supplemented with probiotic, prebiotic and synbiotic compared with the control group. Feed restriction decreased the feed intake when each group in this trial was compared with its corresponding one in the unrestricted trial.

The feed conversion ratio in the three additive groups $(2,3$, and 4) was $1.13,1.18$, and 1.11 at the starter, 1.62, 1.67, and 1.58 at the grower, and 1.27, 2.05, and 1.91 at the finisher, respectively, compared with $1.26,1.76$, and 2.23 at the three phases for the control. The cumulative FCR was 1.60, 1.64, and 1.56 at the end of the experiment in the three additive groups $(2,3$, and 4) compared with 1.71 for the control. It was noted that there was no great difference among groups, and also the improving effect was not so large. Moreover, restriction decreased the feed intake but improved the feed conversion ratio. The FCR in the restricted control reached 1.26, 1.76, and 2.23 at the starter, grower and finisher periods, respectively compared with $1.40,1.83$, and 2.76 in the ad libitum control and with a cumulative ratio of 1.71 in restriction and 1.94 in ad libitum. Also, the feed efficiency of each additive group in this trial was higher than its corresponding one in the unrestricted trial.

Addition of additives with restriction improved the cost of $\mathrm{kg}$ gain, at the starter, to be $4.46,4.81$, and $4.46 \mathrm{LE}$ in the three groups $(2,3$, and 4$)$, respectively, while in the control it was 4.94 LE; the prebiotic had the least effect. The probiotic and synbiotic continued to be the most effective in the grower and finisher periods. In the total period, each $\mathrm{kg}$ gain cost 5.66, 5.56 LE in probiotic and synbiotic groups, respectively, compared with 6.07 LE in the control. Prebiotic was the least effective and the $\mathrm{kg}$ gain in this group cost 5.90 LE Feed restriction improved the feed cost of production in the control to be 4.94, 6.28, and 7.27 LE at the starter, grower, and finisher periods, respectively, compared to 5.49, 6.53, and 9.0 LE in the ad libitum control group, an improvement reaching a maximum of $19 \%$. Similar to the control, the feed cost of production in the additive groups in this trial was lower than its corresponding ones in the ad libitum trial. 


\section{Blood and serum biochemical indices}

Blood parameters were measured at the end of starter, grower and finisher periods. Their data are shown in Table 4.

Trial I (Ad libitum feeding): Hemoglobin level in the control group was $14.05,15.28$, and $16.20 \mathrm{~g} / \mathrm{dL}$ at 3rd, 6th, and 8th week, respectively, while, packed cell volume was $30.91 \%, 33.62 \%$, and $36.64 \%$. The values of hemoglobin and packed cell volume in the additive groups $(2,3$, and 4$)$ were in the same range of that of the control. Thus, there were no statistical differences $(\mathrm{p}>0.05)$ in hemoglobin and packed cell volume percentage between the control and the other groups in ad libitum feeding. In addition, total protein levels, in the control, showed 2.86, 3.05, and $3.52 \mathrm{~g} / \mathrm{dL}$ at $3 \mathrm{rd}, 6 \mathrm{th}$, and 8 th week, respectively. The readings with albumin were $1.46,1.78$, and $1.95 \mathrm{~g} / \mathrm{dL}$ and with globulin were $1.40,1.27$, and $1.57 \mathrm{~g} / \mathrm{dL}$ at the three age periods. In the control, serum glucose concentration was $241.33,245.0$, and $269.33 \mathrm{mg} / \mathrm{dL}$, while total cholesterol was $132.67,141.67$, and $157.33 \mathrm{mg} / \mathrm{dL}$ at $3 \mathrm{rd}, 6 \mathrm{th}$, and 8th week, respectively. Also, the values of the tested serum parameters in the additive groups $(2,3$, and 4$)$ were similar to that of the control, resulting in no statistical differences ( $p>0.05$ ) among the treatments.

Trial II (Restricted feeding): There were no statistical differences ( $\mathrm{p}>0.05)$ among the treatments in hemoglobin and serum parameters. However, packed cell volume $\%$ was increased $(\mathrm{p}<0.05)$, at the 8th week only, in the additive groups compared to the control. Moreover, hemoglobin, packed cell volume, total protein and albumin levels were not affected $(\mathrm{p}>0.05)$ by feed restriction. Nevertheless, there was a slight significant $(p<0.05)$ decrease in globulin due to restriction. Also, restriction of feed slightly decreased the level of serum glucose at the 3rd week of age, but significantly $(\mathrm{p}<0.05)$, by only $20 \mathrm{mg} / \mathrm{dL}$. Serum total cholesterol concentration was not affected by feeding regime except a slight decrease $(\mathrm{p}<0.05)$ in feed restriction at the 8 th week of age (132.67 vs $157.33 \mathrm{mg} / \mathrm{dL})$. Moreover, there were no significant differences ( $p>0.05)$ in blood and serum parameters between the feed additive treatments in this trial with its corresponding ones in the unrestricted trial.

\section{Carcass characteristics}

Carcass traits were determined at the end of grower and finisher periods. Their results are presented in Table 5.

Trial I (Ad libitum feeding): At the end of the grower period, feeding the three kinds of additives increased $(\mathrm{p}<0.05)$ the relative weight of gizzard and proventriculus, spleen, bursa of fabricius, and the two ceca (except the probiotic). The most important effect in the three additives was the decrease $(p<0.05)$ in the visible fat. However, the additives did not affect $(p>0.05)$ the carcass yield, liver, heart, and small intestine.

Table 4. Blood and serum biochemical indices in the different experimental groups at the end of the starter, grower and finisher periods (Mean \pm SEM)

\begin{tabular}{|c|c|c|c|c|c|c|c|c|}
\hline \multirow{3}{*}{ Parameters } & \multicolumn{4}{|c|}{ Trial I (Ad libitum feeding) } & \multicolumn{4}{|c|}{ Trial II (Restricted feeding) } \\
\hline & Control & Probiotic & Prebiotic & Synbiotic & Control & Probiotic & Prebiotic & Synbiotic \\
\hline & 1 & 2 & 3 & 4 & 1 & 2 & 3 & 4 \\
\hline \multicolumn{9}{|l|}{ Starter phase } \\
\hline Hemoglobin (g/dL) & $14.05 \pm 0.44^{\mathrm{Aa}}$ & $15.05 \pm 0.27^{\mathrm{Aa}}$ & $14.34 \pm 0.69^{\mathrm{Aa}}$ & $15.60 \pm 0.53^{\mathrm{Aa}}$ & $13.76 \pm 0.54^{\mathrm{Aa}}$ & $14.34 \pm 0.69^{\mathrm{Aa}}$ & $13.74 \pm 0.23^{\mathrm{Aa}}$ & $13.95 \pm 0.33^{\mathrm{Aa}}$ \\
\hline Packed cell volume (\%) & $30.91 \pm 0.96^{\mathrm{Aa}}$ & $33.14 \pm 0.62^{\mathrm{Aa}}$ & $31.56 \pm 1.48^{\mathrm{Aa}}$ & $34.48 \pm 1.12^{\mathrm{Aa}}$ & $30.62 \pm 0.55^{\mathrm{Aa}}$ & $31.58 \pm 1.52^{\mathrm{Aa}}$ & $30.26 \pm 0.53^{\mathrm{Aa}}$ & $30.63 \pm 0.78^{\mathrm{Aa}}$ \\
\hline Total protein $(\mathrm{g} / \mathrm{dL})$ & $2.86 \pm 0.21^{\mathrm{Aa}}$ & $2.99 \pm 0.14^{\mathrm{Aa}}$ & $2.84 \pm 0.15^{\mathrm{Aa}}$ & $2.98 \pm 0.13^{\mathrm{Aa}}$ & $2.52 \pm 0.10^{\mathrm{Aa}}$ & $2.70 \pm 0.09^{\mathrm{Aa}}$ & $2.66 \pm 0.11^{\mathrm{Aa}}$ & $2.75 \pm 0.16^{\mathrm{Aa}}$ \\
\hline Albumin (g/dL) & $1.46 \pm 0.14^{\mathrm{Aa}}$ & $1.60 \pm 0.11^{\mathrm{Aa}}$ & $1.61 \pm 0.03^{\mathrm{Aa}}$ & $1.68 \pm 0.04^{\mathrm{Aa}}$ & $1.47 \pm 0.09^{\mathrm{Aa}}$ & $1.51 \pm 0.10^{\mathrm{Aa}}$ & $1.47 \pm 0.04^{\mathrm{Aa}}$ & $1.52 \pm 0.05^{\mathrm{Aa}}$ \\
\hline Globulin (g/dL) & $1.40 \pm 0.10^{\text {Aa }}$ & $1.39 \pm 0.03^{\mathrm{Aa}}$ & $1.23 \pm 0.11^{\mathrm{Aa}}$ & $1.30 \pm 0.09^{\mathrm{Aa}}$ & $1.05 \pm 0.03^{\mathrm{Aa}}$ & $1.19 \pm 0.1^{\text {Aa }}$ & $1.19 \pm 0.06^{\mathrm{Aa}}$ & $1.23 \pm 0.05^{\mathrm{Aa}}$ \\
\hline Glucose (mg/dL) & $241.33 \pm 4.81^{\mathrm{Aa}}$ & $248.33 \pm 16.01^{\mathrm{Aa}}$ & $237.67 \pm 5.24^{\mathrm{Aa}}$ & $236.67 \pm 10.13^{\mathrm{Aa}}$ & $221.00 \pm 4.93^{\mathrm{Aa}}$ & $221.33 \pm 7.31^{\mathrm{Aa}}$ & $215.33 \pm 10.84^{\mathrm{Aa}}$ & $217.67 \pm 12.41^{\text {Aa }}$ \\
\hline Total cholesterol (mg/dL) & $132.67 \pm 11.05^{\mathrm{Aa}}$ & $129.16 \pm 3.69^{\mathrm{Aa}}$ & $123.33 \pm 11.47^{\mathrm{Aa}}$ & $120.33 \pm 4.67^{\text {Aa }}$ & $121.34 \pm 11.20^{\mathrm{Aa}}$ & $121.33 \pm 12.68^{\mathrm{Aa}}$ & $118.33 \pm 7.51^{\mathrm{Aa}}$ & $116.67 \pm 9.53^{\mathrm{Aa}}$ \\
\hline \multicolumn{9}{|l|}{ Grower phase } \\
\hline Hemoglobin (g/dL) & $15.28 \pm 0.26^{\mathrm{Aa}}$ & $15.81 \pm 0.34^{\mathrm{Aa}}$ & $15.07 \pm 0.44^{\mathrm{Aa}}$ & $16.21 \pm 0.79^{\mathrm{Aa}}$ & $13.92 \pm 0.25^{\mathrm{Aa}}$ & $14.80 \pm 0.44^{\mathrm{Aa}}$ & $14.22 \pm 0.23^{\mathrm{Aa}}$ & $14.5 \pm 0.58^{\mathrm{Aa}}$ \\
\hline Packed cell volume (\%) & $33.62 \pm 0.57^{\mathrm{Aa}}$ & $34.78 \pm 0.61^{\mathrm{Aa}}$ & $33.25 \pm 0.88^{\mathrm{Aa}}$ & $35.46 \pm 1.68^{\mathrm{Aa}}$ & $31.08 \pm 1.31^{\mathrm{Aa}}$ & $32.62 \pm 1.24^{\mathrm{Aa}}$ & $31.27 \pm 0.53^{\mathrm{Aa}}$ & $31.86 \pm 1.32^{\mathrm{Aa}}$ \\
\hline Total protein (g/dL) & $3.05 \pm 0.09^{\mathrm{Aa}}$ & $3.26 \pm 0.12^{\mathrm{Aa}}$ & $3.04 \pm 0.12^{\mathrm{Aa}}$ & $3.31 \pm 0.05^{\mathrm{Aa}}$ & $2.69 \pm 0.13^{\mathrm{Aa}}$ & $3.09 \pm 0.31^{\mathrm{Aa}}$ & $3.02 \pm 0.16^{\mathrm{Aa}}$ & $3.21 \pm 0.19^{\mathrm{Aa}}$ \\
\hline Albumin $(\mathrm{g} / \mathrm{dL})$ & $1.78 \pm 0.04^{\mathrm{Aa}}$ & $1.93 \pm 0.21^{\mathrm{Aa}}$ & $1.86 \pm 0.20^{\mathrm{Aa}}$ & $1.99 \pm 0.07^{\mathrm{Aa}}$ & $1.70 \pm 0.17^{\mathrm{Aa}}$ & $1.80 \pm 0.12^{\mathrm{Aa}}$ & $1.78 \pm 0.28^{\mathrm{Aa}}$ & $1.85 \pm 0.07^{\mathrm{Aa}}$ \\
\hline Globulin (g/dL) & $1.27 \pm 0.06^{\mathrm{Aa}}$ & $1.33 \pm 0.10^{\mathrm{Aa}}$ & $1.18 \pm 0.08^{\mathrm{Aa}}$ & $1.32 \pm 0.02^{\mathrm{Aa}}$ & $0.99 \pm 0.04^{\mathrm{Aa}}$ & $1.29 \pm 0.13^{\mathrm{Aa}}$ & $1.24 \pm 0.12^{\mathrm{Aa}}$ & $1.36 \pm 0.23^{\mathrm{Aa}}$ \\
\hline Glucose (mg/dL) & $245.0 \pm 5.57^{\mathrm{Aa}}$ & $269.33 \pm 20.28^{\mathrm{Aa}}$ & $247.0 \pm 10.69^{\mathrm{Aa}}$ & $252.33 \pm 9.95^{\mathrm{Aa}}$ & $232.0 \pm 8.39^{\mathrm{Aa}}$ & $240.67 \pm 7.88^{\mathrm{Aa}}$ & $234.33 \pm 13.78^{\text {Aa }}$ & $237.0 \pm 8.96^{\mathrm{Aa}}$ \\
\hline Total cholesterol (mg/dL) & $141.67 \pm 11.72^{\mathrm{Aa}}$ & $136.00 \pm 10.26^{\mathrm{Aa}}$ & $133.0 \pm 8.72^{\mathrm{Aa}}$ & $130.67 \pm 13.62^{\mathrm{Aa}}$ & $124.67 \pm 8.45^{\mathrm{Aa}}$ & $125.67 \pm 11.05^{\mathrm{Aa}}$ & $119.33 \pm 9.39^{\mathrm{Aa}}$ & $119.33 \pm 5.81^{\text {Aa }}$ \\
\hline \multicolumn{9}{|l|}{ Finisher phase } \\
\hline Hemoglobin (g/dL) & $16.20 \pm 0.41^{\text {Aa }}$ & $17.03 \pm 0.33^{\mathrm{Aa}}$ & $16.40 \pm 0.27^{\mathrm{Aa}}$ & $17.57 \pm 0.96^{\mathrm{Aa}}$ & $15.38 \pm 0.65^{\mathrm{Aa}}$ & $16.89 \pm 0.38^{\mathrm{Aa}}$ & $16.42 \pm 0.38^{\mathrm{Aa}}$ & $16.57 \pm 0.33^{\mathrm{Aa}}$ \\
\hline Packed cell volume (\%) & $35.64 \pm 0.89^{\mathrm{Aa}}$ & $37.56 \pm 0.69^{\mathrm{Aa}}$ & $36.02 \pm 0.55^{\mathrm{Aa}}$ & $37.95 \pm 1.02^{\mathrm{Aa}}$ & $33.53 \pm 0.37^{\mathrm{Aa}}$ & $37.15 \pm 0.86^{\mathrm{Ab}}$ & $35.98 \pm 0.70^{\mathrm{Ab}}$ & $36.44 \pm 0.67^{\mathrm{Ab}}$ \\
\hline Total protein (g/dL) & $3.52 \pm 0.05^{\mathrm{Aa}}$ & $3.72 \pm 0.24^{\mathrm{Aa}}$ & $3.61 \pm 0.21^{\mathrm{Aa}}$ & $3.91 \pm 0.18^{\mathrm{Aa}}$ & $3.16 \pm 0.40^{\mathrm{Aa}}$ & $3.55 \pm 0.28^{\mathrm{Aa}^{\mathrm{a}}}$ & $3.53 \pm 0.42^{\mathrm{Aa}}$ & $3.65 \pm 0.27^{\mathrm{Aa}}$ \\
\hline Albumin (g/dL) & $1.95 \pm 0.05^{\mathrm{Aa}}$ & $2.18 \pm 0.19^{\mathrm{Aa}}$ & $2.04 \pm 0.14^{\mathrm{Aa}}$ & $2.49 \pm 0.26^{\mathrm{Aa}}$ & $1.76 \pm 0.13^{\mathrm{Aa}}$ & $2.05 \pm 0.17^{\mathrm{Aa}}$ & $1.98 \pm 0.17^{\mathrm{Aa}}$ & $2.09 \pm 0.12^{\mathrm{Aa}}$ \\
\hline Globulin (g/dL) & $1.57 \pm 0.02^{\mathrm{Aa}}$ & $1.54 \pm 0.07^{\mathrm{Aa}}$ & $1.57 \pm 0.07^{\mathrm{Aa}}$ & $1.42 \pm 0.15^{\mathrm{Aa}}$ & $1.40 \pm 0.02^{\mathrm{Aa}}$ & $1.50 \pm 0.16^{\mathrm{Aa}}$ & $1.55 \pm 0.26^{\mathrm{Aa}}$ & $1.56 \pm 0.12^{\mathrm{Aa}}$ \\
\hline Glucose (mg/dL) & $269.33 \pm 7.17^{\mathrm{Aa}}$ & $290.33 \pm 15.60^{\text {Aa }}$ & $270.33 \pm 13.78^{\mathrm{Aa}}$ & $281.67 \pm 34.59^{\mathrm{Aa}}$ & $254.33 \pm 12.72^{\mathrm{Aa}}$ & $274.67 \pm 21.83^{\mathrm{Aa}}$ & $262.0 \pm 15.50^{\mathrm{Aa}}$ & $263.0 \pm 11.79^{\mathrm{Aa}}$ \\
\hline Total cholesterol (mg/dL) & $157.33 \pm 11.55^{\mathrm{Aa}}$ & $152.33 \pm 10.48^{\mathrm{Aa}}$ & $148.33 \pm 4.33^{\mathrm{Aa}}$ & $138.0 \pm 5.51^{\mathrm{Aa}}$ & $132.67 \pm 12.14^{\mathrm{Aa}}$ & $126.67 \pm 6.74^{\mathrm{Aa}}$ & $123.34 \pm 16.76^{\mathrm{Aa}}$ & $122.67 \pm 13.24^{\mathrm{Aa}}$ \\
\hline
\end{tabular}

SEM, standard error of the mean.

$a, b$ Means within the same row (in each trial independently) with different superscripts are significantly different $(p<0.05)$.

$A, B$ Means within the same row (in both trials together) with different superscripts are significantly different $(p<0.05)$. 
Table 5. Relative carcass and organ weights (\% of body weight) of the different experimental groups at the end of the grower and finisher periods (Mean \pm SEM)

\begin{tabular}{|c|c|c|c|c|c|c|c|c|}
\hline \multirow{3}{*}{ Character (\%) } & \multicolumn{4}{|c|}{ Trial I (Ad libitum feeding) } & \multicolumn{4}{|c|}{ Trial II (Restricted feeding) } \\
\hline & Control & Probiotic & Prebiotic & Synbiotic & Control & Probiotic & Prebiotic & Synbiotic \\
\hline & 1 & 2 & 3 & 4 & 1 & 2 & 3 & 4 \\
\hline \multicolumn{9}{|l|}{ Grower phase } \\
\hline Dressing value & $69.36 \pm 0.88^{\text {Aa }}$ & $70.99 \pm 0.39^{\text {Aa }}$ & $70.70 \pm 0.32^{\mathrm{Aa}}$ & $71.63 \pm 1.16^{\mathrm{Aa}}$ & $69.11 \pm 0.86^{\mathrm{Aa}}$ & $69.69 \pm 0.18^{\mathrm{Aa}}$ & $69.60 \pm 0.43^{\mathrm{Aa}}$ & $69.91 \pm 0.97^{\text {Aa }}$ \\
\hline Liver & $2.77 \pm 0.09^{\mathrm{Ba}}$ & $2.82 \pm 0.06^{\mathrm{Ba}}$ & $2.74 \pm 0.02^{\mathrm{Ba}}$ & $2.85 \pm 0.06^{\mathrm{Ba}}$ & $2.15 \pm 0.03^{\mathrm{Aa}}$ & $3.11 \pm 0.03^{\mathrm{cc}}$ & $2.75 \pm 0.01^{\mathrm{Bb}}$ & $3.14 \pm 0.01^{\mathrm{cc}}$ \\
\hline Gizzard and proventriculus & $2.47 \pm 0.03^{\mathrm{Aa}}$ & $2.72 \pm 0.17^{\mathrm{ABCab}}$ & $2.89 \pm 0.04^{\mathrm{CDb}}$ & $2.79 \pm 0.03^{B C D b}$ & $2.58 \pm 0.07^{\mathrm{ABa}}$ & $3.03 \pm 0.04^{\mathrm{Db}}$ & $3.14 \pm 0.03^{\mathrm{Db}}$ & $3.08 \pm 0.04^{\mathrm{Eb}}$ \\
\hline Heart & $0.72 \pm 0.03^{\mathrm{Aa}}$ & $0.66 \pm 0.02^{\mathrm{Aa}}$ & $0.69 \pm 0.01^{\text {Aa }}$ & $0.70 \pm 0.02^{\mathrm{Aa}}$ & $0.65 \pm 0.02^{\mathrm{Aa}}$ & $0.71 \pm 0.02^{\mathrm{Ab}}$ & $0.74 \pm 0.01^{\mathrm{Ab}}$ & $0.82 \pm 0.02^{A C}$ \\
\hline Spleen & $0.09 \pm 0.06^{\mathrm{Aa}}$ & $0.20 \pm 0.01^{\mathrm{cb}}$ & $0.20 \pm 0.01^{\mathrm{cb}}$ & $0.20 \pm 0.01^{\mathrm{cb}}$ & $0.15 \pm 0.01^{\mathrm{Ba}}$ & $0.16 \pm 0.01^{\mathrm{Ba}}$ & $0.15 \pm 0.01^{\mathrm{Ba}}$ & $0.17 \pm 0.01^{\mathrm{Ca}}$ \\
\hline Bursa of fabricius & $0.09 \pm 0.01^{\mathrm{Aa}}$ & $0.13 \pm 0.01^{\mathrm{Ab}}$ & $0.12 \pm 0.00^{\mathrm{Ab}}$ & $0.13 \pm 0.01^{\mathrm{Ab}}$ & $0.10 \pm 0.00^{\mathrm{Aa}}$ & $0.13 \pm 0.01^{\mathrm{Aa}}$ & $0.13 \pm 0.00^{\mathrm{Aa}}$ & $0.15 \pm 0.01^{\text {Aa }}$ \\
\hline Small intestine & $3.51 \pm 0.03^{\mathrm{Aa}}$ & $3.52 \pm 0.02^{\mathrm{Aa}}$ & $3.50 \pm 0.01^{\mathrm{Aa}}$ & $3.64 \pm 0.26^{\mathrm{ABa}}$ & $3.67 \pm 0.01^{\mathrm{ABa}}$ & $3.89 \pm 0.04^{B C C}$ & $3.79 \pm 0.01^{\mathrm{ABCb}}$ & $4.07 \pm 0.01^{\mathrm{Cd}}$ \\
\hline Two caeca & $0.48 \pm 0.00^{\mathrm{Aa}}$ & $0.47 \pm 0.02^{\mathrm{Aa}}$ & $0.62 \pm 0.01^{\mathrm{cb}}$ & $0.73 \pm 0.01^{D C}$ & $0.52 \pm 0.03^{\mathrm{ABa}}$ & $0.54 \pm 0.01^{A B a}$ & $0.65 \pm 0.02^{\mathrm{cb}}$ & $0.74 \pm 0.03^{D c}$ \\
\hline Visible fat"1) & $2.30 \pm 0.16^{\mathrm{cb}}$ & $1.20 \pm 0.03^{B a}$ & $0.94 \pm 0.25^{\mathrm{ABa}}$ & $1.07 \pm 0.01^{\mathrm{Ba}}$ & $1.18 \pm 0.01^{B C}$ & $0.98 \pm 0.03^{\mathrm{ABb}}$ & $0.67 \pm 0.08^{\mathrm{Aa}}$ & $0.87 \pm 0.02^{\mathrm{ABB}}$ \\
\hline \multicolumn{9}{|l|}{ Finisher phase } \\
\hline Dressing value & $71.71 \pm 1.33^{\mathrm{Aa}}$ & $73.72 \pm 0.79^{\mathrm{Aa}}$ & $73.75 \pm 1.49^{\mathrm{Aa}}$ & $73.99 \pm 0.80^{\mathrm{Aa}}$ & $70.13 \pm 1.64^{\mathrm{Aa}}$ & $72.57 \pm 1.66^{\mathrm{Aa}}$ & $72.03 \pm 0.26^{\mathrm{Aa}}$ & $72.94 \pm 0.69^{\mathrm{Aa}}$ \\
\hline Liver & $2.26 \pm 0.02^{\mathrm{Aa}}$ & $2.51 \pm 0.06^{B C b}$ & $2.33 \pm 0.02^{\mathrm{Aa}}$ & $2.59 \pm 0.01^{\mathrm{cb}}$ & $2.30 \pm 0.01^{\mathrm{Aa}}$ & $2.54 \pm 0.01^{\mathrm{cc}}$ & $2.45 \pm 0.01^{\mathrm{Bb}}$ & $2.66 \pm 0.02^{\mathrm{Dd}}$ \\
\hline Gizzard and proventriculus & $2.30 \pm 0.02^{\mathrm{Ba}}$ & $2.30 \pm 0.02^{\mathrm{Ba}}$ & $2.47 \pm 0.01^{\mathrm{cb}}$ & $2.35 \pm 0.03^{\mathrm{Ba}}$ & $2.32 \pm 0.04^{B a}$ & $2.32 \pm 0.02^{\mathrm{Aa}}$ & $2.53 \pm 0.04^{\mathrm{cb}}$ & $2.46 \pm 0.02^{\mathrm{Db}}$ \\
\hline Heart & $0.87 \pm 0.01^{\mathrm{Ad}}$ & $0.67 \pm 0.01^{\mathrm{Aa}}$ & $0.81 \pm 0.02^{\mathrm{Ac}}$ & $0.71 \pm 0.00^{\mathrm{Ab}}$ & $0.78 \pm 0.03^{\mathrm{Aa}}$ & $0.73 \pm 0.02^{\mathrm{Aa}}$ & $0.79 \pm 0.02^{\mathrm{Aa}}$ & $0.77 \pm 0.01^{\text {Aa }}$ \\
\hline Spleen & $0.13 \pm 0.01^{\mathrm{Aa}}$ & $0.15 \pm 0.01^{\mathrm{ABa}}$ & $0.15 \pm 0.01^{\mathrm{ABa}}$ & $0.17 \pm 0.01^{\mathrm{ABa}}$ & $0.15 \pm 0.01^{\mathrm{ABa}}$ & $0.18 \pm 0.01^{A B a}$ & $0.17 \pm 0.01^{\mathrm{ABa}}$ & $0.22 \pm 0.02^{\mathrm{Ca}}$ \\
\hline Bursa of fabricius & $0.06 \pm 0.01^{\mathrm{Aa}}$ & $0.08 \pm 0.01^{\mathrm{Aa}}$ & $0.08 \pm 0.01^{\mathrm{Aa}}$ & $0.09 \pm 0.00^{\mathrm{Aa}}$ & $0.06 \pm 0.00^{\mathrm{Aa}}$ & $0.07 \pm 0.00^{\mathrm{Aa}}$ & $0.06 \pm 0.00^{\mathrm{Aa}}$ & $0.07 \pm 0.00^{\mathrm{Aa}}$ \\
\hline Small intestine & $2.56 \pm 0.02^{\mathrm{Aa}}$ & $2.61 \pm 0.07^{\mathrm{Aa}}$ & $2.58 \pm 0.02^{\mathrm{Aa}}$ & $2.79 \pm 0.01^{\mathrm{Ba}}$ & $2.57 \pm 0.06^{\mathrm{Aa}}$ & $2.58 \pm 0.03^{\mathrm{Aa}}$ & $2.57 \pm 0.03^{\mathrm{Aa}}$ & $2.79 \pm 0.05^{\mathrm{Ba}}$ \\
\hline Two caeca & $0.44 \pm 0.03^{\mathrm{Aa}}$ & $0.49 \pm 0.02^{\mathrm{Aab}}$ & $0.54 \pm 0.00^{\mathrm{ABb}}$ & $0.66 \pm 0.03^{D C}$ & $0.57 \pm 0.02^{\mathrm{ca}}$ & $0.56 \pm 0.01^{\mathrm{ca}}$ & $0.57 \pm 0.01^{\mathrm{ca}}$ & $0.59 \pm 0.01^{\mathrm{Ca}}$ \\
\hline Visible fat ${ }^{1)}$ & $2.64 \pm 0.01^{\mathrm{Fd}}$ & $2.12 \pm 0.01^{\mathrm{Ec}}$ & $0.96 \pm 0.05^{\mathrm{Ba}}$ & $1.71 \pm 0.06^{\mathrm{Db}}$ & $1.49 \pm 0.09^{c b}$ & $0.75 \pm 0.05^{\mathrm{Aa}}$ & $0.64 \pm 0.05^{\mathrm{Aa}}$ & $0.75 \pm 0.03^{\mathrm{Aa}}$ \\
\hline
\end{tabular}

SEM, standard error of the mean.

${ }^{\text {a-d }}$ Means within the same row (in each trial independently) with different superscripts are significantly different $(p<0.05)$.

A-F Means within the same row (in both trials together) with different superscripts are significantly different $(p<0.05)$.

${ }^{1)}$ Visible fat is the fat found around the viscera and subcutaneously.

At the end of the finisher period, the additives had inconsistent trend, an increase $(\mathrm{p}<0.05)$ in the relative weight of liver in probiotic and synbiotic, gizzard, and proventriculus in prebiotic, and the two caeca in prebiotic and synbiotic. In addition, a decrease in the relative weight of heart and visible fat was found in probiotic, prebiotic and synbiotic. However, the feed additives did not influence $(\mathrm{p}>0.05)$ the carcass yield, spleen, bursa of fabricius, and small intestine.

Trial II (Restricted feeding): At the end of the grower period, addition of the additives with restricted feeding did not affect the carcass yield and the relative weight of internal organs, except a significant increase $(\mathrm{p}<0.05)$ in the liver, gizzard and proventriculus, heart, small intestine, and the two ceca (except the probiotic). In addition, the additives decreased $(\mathrm{p}<0.05)$ the visible fat than the restricted control. Moreover, the feed restriction and additive groups decreased $(\mathrm{p}<0.05)$ the visible fat but increased $(p<0.05)$ the gizzard and proventriculus, and small intestine, when compared with its corresponding ones in the unrestricted trial. The relative weight of liver was higher in probiotic and synbiotic, but lower in restricted control when compared with the corresponding groups in the ad libitum trial.

At the end of the finisher period, use of the three additives with restricted feeding did not make any change to the carcass yield and the relative weight of internal organs, except an increase $(\mathrm{p}<0.05)$ in the liver in the three groups, and gizzard and proventriculus in prebiotic and synbiotic. Nevertheless, the additives decreased significantly $(\mathrm{p}<0.05)$ the visible fat. Moreover, the restriction and additive addition decreased more the visible fat, when compared with its corresponding groups in the unrestricted trial. While, the relative weight of the liver was higher in prebiotic only in comparison with the ad libitum prebiotic group.

\section{DISCUSSION}

In this study some attempts were made to improve the feed utilization and conversion using well-famed, biological feed additives - probiotic, prebiotic and synbiotic - in addition to the benefit gained from the feed restriction program. Feed restriction is one of the feeding strategies in which the feed is put off for several hours during the day in order to improve feed conversion and reduce the fat deposition in carcasses [5]. Feed restriction may represent an effective tool for improving the economic return. Because of the feed restriction, feed intake and growth were expected to be reduced with an end weight less than normal in spite of an improvement in feed conversion and carcass quality. The biological additives probiotic, prebiotic and synbiotic were used to test their effect in increasing feed intake so improving growth and increasing the end weight.

\section{Performance and feed cost of production}

Trial I (Ad libitum feeding): At the end of the experiment, the 
BW of birds supplemented with probiotic, prebiotic and synbiotic was increased to be $2,774,2,344$, and 2,907 g, respectively, vs $2,171 \mathrm{~g}$ for the control. This increase in BW represents about $128 \%, 108 \%$, and $134 \%$ of the control (100\%) for the additive groups respectively, indicating that the prebiotic was the lowest in effect while synbiotic was the highest. The effect of synbiotic could be related to synergism between probiotic and prebiotic, which increase the digestion and absorption of nutrients [3]. The marked improvement in BW of chicks fed on supplemented diets in this study is fully consistent with the results of the previous studies [12,13]. In contrast, Salehimanesh et al [14] reported that using these additives in the broiler rations had no significant effects on BW and gain. Variations among reports of researches could be related to bird age, sex, breed, overall farm hygiene, environmental stress, type, concentration and dosage, methods of using, and frequency of application [14].

The mortality in this trial was low and varied between one to two birds throughout the different groups, indicating no effect of dietary treatments on mortality. But these losses might be due to the climatic influence and individual differences. The same finding was reported in Sarangi et al [13] who concluded that mortality $\%$ was not significantly affected by using the feed additives. However, Riad et al [15] reported that the addition of feed additives decreased the mortality rate. The reduction in mortality was attributed to the inhibitory effects of these additives towards enteric micro-organisms via modifying the intestinal $\mathrm{pH}$.

The feed intake started to increase at the grower period in the probiotic, prebiotic and synbiotic, but in the prebiotic group there was no more increase at the finisher. At the end of the experiment, the increase in feed consumption reached about $112 \%, 101 \%$, and $114 \%$ for probiotic, prebiotic and synbiotic respectively, compared with the control. These results indicated that the probiotic and synbiotic had the same effect and the prebiotic with no clear effect. So, addition of additives, especially the probiotic and synbiotic, seems to increase the appetite and feed intake. The increase in feed intake was observed also in the study of Riad et al [15]. However, other studies [13,14] found that feed intake of broilers did not differ significantly by dietary inclusion of probiotics. The effect of probiotic, prebiotic and synbiotic on the efficiency of feed utilization started from the starter period, however, the increase in feed intake and weight commenced at the grower period. The efficiency was improved in feed additive groups with the clearest effect in synbiotic and probiotic groups. Addition of additives saved $0.30 \mathrm{~kg}$ feed for every $1 \mathrm{~kg}$ gain on maximum and $0.12 \mathrm{~kg}$ on minimum, decreasing the end cost of $1 \mathrm{~kg}$ live BW. The results totally coincided with the observations of Riad et al [15] who reported that using probiotic, prebiotic and their combination in broiler diets lowered feed conversion. The improvement may be due to that biological feed additives alter the intestinal $\mathrm{pH}$ which modifies both microbial population and nutrient absorption improving the efficiency of feed utilization [1]. In addition, the additives can increase the villus height and intestinal length, resulting in an increased surface area capable of greater absorption of available nutrients [16]. Contradictory results were obtained by Sarangi et al [13] who found a non-significant difference in feed conversion ratio of broiler chickens in prebiotic, probiotic, and synbiotic groups when compared with control group.

The additives supplementation in this study greatly reduced the feed cost of production. The obtained results agreed with Riad et al [15] and Saiyed et al [12] who reported that supplementation of broiler diets with biological additives have a positive effect on the economic return. Addition of feed additives to broiler diets was found to enhance BW gains, feed conversion ratio, stimulated bird's immunity and reduced mortality rate and subsequently improved net return and cost of production [14]. The lowest feed cost per kg live weight of chickens was found in the experimental groups containing probiotic and synbiotic which had also the lowest FCR compared to the other two groups (control and prebiotic).

Trial II (Restricted feeding): This trial tested the effect of the additives in correcting the negative effect of restriction on chick performance. The effect of the feed restriction was clear in the control, while it was nullified in the additive groups especially in the probiotic and synbiotic. The best of the three was the probiotic followed by the synbiotic, while the prebiotic in spite of its being effective in nullifying the effect of restriction, and was the lowest. So, it is wise to recommend addition of probiotic, prebiotic or synbiotic with restriction. Restricted groups reached the same weight as with ad libitum fed control, as in prebiotic, or exceeded by $11 \%$ and $7 \%$ in probiotic and synbiotic, respectively. Congruent with our findings, various researchers have reported lower weight gains and market weights in feedrestricted vs full-fed birds $[17,18]$. Contrasting results have been cited by Mahmud et al [19]. In restriction, the growth decreased because the chicken consuming protein and energy less than their needs. Probiotics had shown to alleviate the stress caused by feed restriction and improve the immunocompetence of birds [9]. The amount of feed consumed in this trial reached its utmost in the probiotic group; it reached 3,789 g which constitutes $130 \%$ when compared with the control (100\%). The amount consumed in the synbiotic was in the second level of increase, where it reached $122 \%$ compared with the control, while in the prebiotic group the feed intake was the lowest and reached only $116 \%$. So, in spite of feed restriction, 5 hours a day, the additives increased the feed intake with a very clear effect with the probiotic and synbiotic. Comparing the two control groups of both trials, it was found that feed restriction decreased the BW at the end by about $19 \%$ due to a decrease in feed intake reaching $29 \%$. Feed restriction decreased feed intake $22 \%$ in the starter, $27 \%$ in the grower, and $36 \%$ in the finisher. There is no place for a compensatory growth to occur as the birds did not get a period of ad libitum feeding to allow them to 
compensate. Many researches indicated that feed intake was significantly decreased during restriction but become higher than un-restricted birds after ad libitum feeding [17,18]. Saffar and Khajali [9] reported that feed intake of birds on restricted feeding with and without probiotic were significantly lower than the full fed control.

In this trial, the feed efficiency in the three additive groups $(2,3$, and 4$)$ was higher than the control one. The improvement in efficiency did not exceed $0.15 \mathrm{~kg}$ feed for every $\mathrm{kg}$ BW, on maximum. So, adding the probiotic, prebiotic or synbiotic improved the BW due to the increase in feed consumption but not due to the increase in efficiency of utilization. Restriction decreased the feed intake but improved the feed conversion ratio compared with the ad libitum groups. So, restriction is beneficial from the feed conversion point of view but on the other hand decreases feed intake and by turn BW. Adding the three additives corrected the feed intake to a degree more than the control, and corrected the BW to a level more than at feeding ad libitum regime (especially, probiotic and synbiotic vs ad libitum control) and in addition slightly improved the feed conversion ratio. Feed restriction has been observed to improve feed conversion ratio than ad libitum feeding [20]. Poor FCR in ad libitum fed birds could be attributed to availability of less time for digestion, whereas feed restricted birds might have proper time for utilization of nutrients in the feed more efficiently leading to better FCR than full-fed birds. In contrast, Mahmud et al [19] did not report significant differences in feed conversion due to feed restriction. Ultimately, the obtained data showed clearly that the feed utilization was improved when the restricted birds were fed diets supplemented with additives. The effects of diet supplementation with these kinds of additives were almost identical in both restricted and fully fed birds.

Feed restriction decreased the feed cost of production in the control group at the starter, grower, and finisher periods compared to the ad libitum control one. Also, addition of additives with restriction reduced the production cost when compared with non-restricted groups. These results are in agreement with results of previous researchers $[6,21]$ who indicated that feed restriction may be a good potential strategy to reduce the cost of feed in broiler meat production or to counter feed shortages or high cost of feed. Cost of production declined with the restriction because the feed intake declined correspondingly. This is so because feed accounts for $55 \%$ to $75 \%$ of production cost and feed restricted birds generally eat less than unrestricted ones. Moreover, feed restricted birds consumed less feed and found ample time to properly digest, absorb and metabolize [20].

\section{Blood and serum biochemical indices}

Trial I (Ad libitum feeding): Blood parameters were analyzed at the end of the three feeding phases. There were no statistical differences in hemoglobin and packed cell volume levels among the treatments. However, probiotic and synbiotic groups showed higher numerical values than other groups. The results were in line with the findings of Alkhalf et al [22] who found that no differences in hemoglobin $(\mathrm{Hb})$ concentration due the addition of probiotic to the diet of broiler. In contrast, Beski and Sardary [23] reported that probiotics and synbiotics resulted in a significant increase in the concentration of $\mathrm{Hb}$. The higher $\mathrm{Hb}$ concentration in the chicks receiving probiotics and synbiotics may be due to the acidic media of the alimentary tract caused by probiotic fermentation which resulted in better iron salt absorption from the small intestine. This may also cause better vitamin B complex production by useful bacteria, which may result in positively affecting blood-forming processes. Meanwhile, synbiotic could increase the digestibility percentage and availability of many nutrient elements such as proteins, mineral elements and vitamins. Absorption of these nutrients may elevate the concentration of hemoglobin. Packed cell volume \% findings are in agreement with those of Hanamanta et al [24] who found that the addition of probiotic and synbiotic to broiler diet had no significant effects on packed cell volume and $\mathrm{Hb}$.

Addition of probiotic, prebiotic, and synbiotic had no significant effect on total protein, albumin and globulin level. The results were in accordance with the findings of Alkhalf et al [21] reported that supplementing broiler diet with probiotic and prebiotic did not have any effect on total protein, albumin, and globulin. The results also showed that the addition of the three additives did not have any statistical effect on serum glucose level. Mokhtari et al [25] found that serum glucose of broilers was not affected significantly by synbiotics. There was also no effect for the additives addition on serum total cholesterol level but dietary supplemented treatments were numerically low. Ashayerizadeh et al [26] found that serum total cholesterol was reduced significantly by dietary supplementation of probiotic. This could be attributed to reduced absorption and/or synthesis of cholesterol in the gastro-intestinal tract by probiotic supplementation.

Trial II (Restricted feeding): There was no effect of the feed restriction or additives addition on hemoglobin level, total protein and albumin levels. However, packed cell volume percentage was increased by the feed additives at the 8th week only, but was not affected by restriction. This may be due to the acidic media of the gut caused by probiotic fermentation which resulted in better iron absorption and vitamin B complex production by useful bacteria, which may result in increasing the packed cell volume. Moreover, a slight significant decrease in globulin level due to restriction was found, but this level within the normal range ( 0.7 to $2 \mathrm{~g} / \mathrm{dL}$ ). Nassef et al [27] showed that early feed restriction had no significant effect on serum total protein, albumin, and globulins. Also, restriction of feed slightly decreased the level of serum glucose at the 3 rd week only. The results also showed that the addition of the three additives did not have any statistical effect on glucose either in ad libitum 
regime or the restricted one. Klasing [28] have reported that chickens maintain a steady glucose level during feed restriction.

In this trial, there was no effect for the feeding regime on total cholesterol level, except a slight decrease at the 8th week of age. Also, the additives did not affect the total cholesterol in both regimes. Nassef et al [27] showed that early feed restriction had no significant effect on serum cholesterol. In contrast, Klasing [28] mentioned that serum total lipids and triglycerides were lower in restricted broilers than those fed ad libitum. It might be due to the obligate use of considerable levels of triglycerides for energy demand during feed restriction.

\section{Carcass characteristics}

Trial I (Ad libitum feeding): In poultry industry, one of the major concerns is to get a higher yield percentage, saleable products and consequently, to increase the edible portions. Generally, addition of feed additives may increase the rate of metabolism and eventually increased the size of most of the internal organs as observed in this study. The most significant effect of the three additives used in this work was the decrease in visible fat, especially with prebiotic and synbiotic. In contrast, carcass yield was not significantly affected by dietary treatments. Our results coincide with the observations of Midilli et al [29] who did not observe any significant impact of probiotic and Mannanoligosaccharides on carcass yield. Mohmud et al [19] reported that the highest abdominal fat percentage value was recorded for birds fed the control diet, while the lowest value was recorded for birds fed the MOS supplemented diet. No clear mechanisms have been reported to be responsible for the reduction of lipid synthesis by prebiotics and probiotic. It might in part be due to increasing beneficial bacteria such as Lactobacillus that decrease the activity of acetyl-CoA carboxylase, which is the ratelimiting enzyme in fatty acids synthesis.

Trial II (Restricted feeding): Feed restriction effects may be either neutral or beneficial for the whole carcass or carcass cut weights. Feed restriction and addition of additives decreased the visible fat and increased most of the giblets in size when compared with ad libitum. Addition of additives decreased more the fat and increased more the giblets. There was no effect for restriction or additives addition on carcass yield. Jahanpour et al [30] reported that both the weight and proportion of carcass cuts were not significantly affected by feed restriction programs.

\section{CONCLUSION}

The obtained results indicate that biological feed additives (probiotic, prebiotic, and synbiotic) could be routinely added to broiler diets, especially when a feed restriction program is followed. Diets supplemented with synbiotic, probiotic, and prebiotic (with and without feed restriction) improved broiler performance, without affecting blood parameters and carcass yield. Restriction and addition of additives resulted in a decreased visible fat of the carcass. Moreover, feed restriction could improve feed conversion ratio and cost of production compared to nonrestricted birds. In addition, biological feed additives may be used as an anti-stress factor in feed restriction. Finally, feed additives can reduce the diet cost, with recommendation of the probiotic and synbiotic which had the lower costs. So, it is advised to restrict feed, and add probiotic or synbiotic to increase weight, improve feed conversion rate and reduce feed cost of production.

\section{CONFLICT OF INTEREST}

We certify that there is no conflict of interest with any financial organization regarding the material discussed in the manuscript.

\section{ACKNOWLEDGMENTS}

The authors would like to thank the Projects Funding and Granting Unit, Research Center, Beni-Suef University, Egypt for the help in financial support of this study.

\section{REFERENCES}

1.Fuller R. Probiotics in man and animals. J Appl Bacterial 1989;66: 265-78.

2.Gibson GR, Roberfroid MB. Dietary modulation of the human colonic microbiota: introducing the concept of prebiotics. J Nutr 1995;125:1401-12.

3.Gruzauskas R., Lekavicius R, Raceviciute-Stupeliene A, Sasyte V, Guarner F. Inulin and oligofructose: Impact on intestinal diseases and disorders. Br J Nutr 2004;93:61-5.

4.Fairchild AS, Grimes JI, Jones FT, et al. Effects of hen age, bio-Mos, and flavomycin on poult susceptibility to oral Escherichia coli challenge. Poult Sci 2001;80:562-71.

5. Weeks CA, Danbury TD, Davies HC, Hunt P, Kestin SC. The behaviour of broiler chickens and its modification by lameness. Appl Anim Behav Sci 2000;67:111-25.

6.Maheri-Sis N, Seyyed NS, Abdolahad S, et al. Effect of feed restriction on growth performance of broiler chickens. Annals Biol Res 2011; 2:247-52.

7.Rosa SP, Avila VS, Jaenisch V. Feed restriction in broilers: how explore your potential. Technical Statement 2000, Concórdia, Embrapa: Swine and Poultry; 2000.

8.Mansoub NH, Kafshnochi M. The effects of probiotics and food restriction on relative growth and serum cholesterol and triglycerides contents in broiler chickens. Global Vet 2010;5:307-11.

9.Saffar A, Khajali F. Application of meal feeding and skip-a-day feeding with or without probiotics for broiler chickens grown at high-altitude to prevent ascites mortality. Am J Anim Vet Sci 2010;5:13-9.

10. AOAC. Official methods of analysis of AOAC International, 18th ed. Gaithersburg, MD: AOAC International; 2005.

11. National Research Council. Nutrient requirements of poultry. 9th 
revised edition. Washington, DC: National Academy Press; 1994.

12. Saiyed MA, Joshi RS, Savaliya FP, et al. Study on inclusion of probiotic, prebiotic and its combination in broiler diet and their effect on carcass characteristics and economics of commercial broilers. Vet World 2015;9:225-31.

13. Sarangi NR, Babu LK, Kumar A, et al. Effect of dietary supplementation of prebiotic, probiotic, and synbiotic on growth performance and carcass characteristics of broiler chickens. Vet World 2016;9:313-9.

14. Salehimanes A, Mohammadi M, Roostaei-Ali M. Effect of dietary probiotic, prebiotic and synbiotic supplementation on performance, immune responses, intestinal morphology and bacterial populations in broilers. J Anim Phys Anim Nutr 2016;100:694-700.

15. Riad SA, Safaa HM, Fatma RM, Salwa S, Hanan AE. Influence of probiotic, prebiotic and/or yeast supplementation in broiler diets on the productivity, immune response and slaughter traits. J Anim Poult Prod 2010;1:45-60.

16. Awad WA, Ghareeb K, Abdel-Raheem S, Bohm J. Effects of dietary inclusion of probiotic and synbiotic on growth performance, organ weights, and intestinal histomorphology of broiler chickens. Poult Sci 2009;88:49-55.

17. Benyi, K, Acheampong-Boateng O, Norris D, Ligaraba TJ. Response of Ross 308 and Hubbard broiler chickens to feed removal for different durations during the day. Trop Anim Health Prod 2010; 42:1421-6

18. Mohammad AR, Zakaria HA. The Effect of quantitative feed restriction during the starter period on compensatory growth and carcass characteristics of broiler chickens. Pakistan J Nutr 2012;11:719-24.

19. Mahmud A, Khattak FM, Ali Z, Pasha T. Effect of early feed restriction on broiler performance, meal feeding on performance, carcass characters and blood constituents of broiler chickens. J Anim Vet Adv 2008;8:2069-74.
20. Mehmood S, Sahota AW, Akram M, et al. Influence of feed restriction regimes on growth performance of broilers with different initial weight categories. J Anim Plant Sci 2013;23:1522-6.

21. Sahraei, M. Feed restriction in broiler chickens production: A Review Global Veterinaria 2012;8:449-58.

22. Alkhalf A, Alhaj M, Al-homidan I. Influence of probiotic supplementation on blood parameters and growth performance in broiler chickens. Saudi J Biol Sci 2010;17:219-25.

23. Beski SS, Al-Sardary SY. Broiler chickens hematology and intestinal integrity. Int J Poult Sci 2015;14:31-6.

24. Hanamanta N, Narayana M, Veena T, Narayana HD, Jayakumar K. Effect of prebiotic, probiotic and G-probiotic SPL on certain haematological parameters in broiler chickens. Vet World 2009;9: 344-6.

25. Mokhrati R, Yazdani AR, Rezaei M, Ghorbani B. The effects of different growth promoters on performance and carcass characteristics of broiler chickens. J Anim Vet Adv 2010;9:2633-9.

26. Ashayerizadeh A, Dabiri N, Mirzadeh K, Ghorbani MR. Effects of dietary inclusion of sev-eral biological feed additives on growth response of broiler chickens. J Cell Anim Biol 2011;5:61-5.

27. Nassef ED, Mustaf S, Tarek K. Effect of feed restriction on growth performance, sudden death syndrome and some blood parameters in broiler chickens. Assiut Vet Med J 2015;61:147.

28. Klasing KC. Comparative avian nutrition. New York: Cab International Press; 1998.

29. Midilli M, Alp M, Kocabagli N, et al. Effects of dietary probiotic and prebiotic supplementation on growth performance and serum IgG concentration of broilers. South Afr J Anim Sci 2008;38:21-7.

30. Jahanpour H, Seidavi A, Qotbi AA, et al. Effects of the level and duration of feeding restriction on carcass components of broilers. Arch Anim Breed 2015;58:99-105. 